This item was submitted to Loughborough's Research Repository by the author.

Items in Figshare are protected by copyright, with all rights reserved, unless otherwise indicated.

\title{
Mobilising the elective diaspora: US-German academic exchanges since
} 1945

\section{PLEASE CITE THE PUBLISHED VERSION}

http://dx.doi.org/10.1111/tran.12062

\section{PUBLISHER}

Wiley / @ Royal Geographical Society (with the Institute of British Geographers)

\section{VERSION}

AM (Accepted Manuscript)

\section{PUBLISHER STATEMENT}

This work is made available according to the conditions of the Creative Commons Attribution-NonCommercialNoDerivatives 4.0 International (CC BY-NC-ND 4.0) licence. Full details of this licence are available at: https://creativecommons.org/licenses/by-nc-nd/4.0/

\section{LICENCE}

CC BY-NC-ND 4.0

\section{REPOSITORY RECORD}

Jons, Heike, Elizabeth Mavroudi, and Michael Heffernan. 2014. "Mobilising the Elective Diaspora: Us-german Academic Exchanges Since 1945". Loughborough University. https://hdl.handle.net/2134/16191. 
Mobilising the elective diaspora: US-German academic exchanges since 1945

Heike Jöns, Elizabeth Mavroudi and Michael Heffernan

Please cite this paper as follows and check for updated volume number:

Jons, H, Mavroudi, E, Heffernan, M (2014) Mobilising the elective diaspora: US-German academic exchanges since 1945, Transactions of the Institute of British Geographers, early view, pp.1-15, DOI: $10.1111 / \operatorname{tran} .12062$

\begin{abstract}
This article responds to recent calls by geographers for more critical, non-essentialist and flexible conceptualisations of diaspora by developing the notion of an 'elective diaspora'. This concept is elaborated using the case study of a specific knowledge diaspora, namely visiting researchers from the USA in the Federal Republic of Germany (FRG), who were funded by the Alexander von Humboldt Foundation, a research agency re-established by the FRG in 1953. The analysis shows how the Humboldt programmes for transnational academic mobility and collaboration drew disproportionately on US-based academics with biographical ties to German-speaking central Europe, which has contributed to the proliferation of US-German knowledge networks in the post-war period and prompts us to reconsider existing notions of diaspora in two ways. First, we emphasise the nuances of the researchers' emotional attachment to German language and culture. We point out that this cannot only be caused by biographical ties through birth and ancestry but also by other family relations, partnerships, friendships, work/living experiences, language skills and cultural knowledge. Second, we stress the elective nature of diasporic identities and belonging by emphasising that individuals can choose whether they wish to support diasporic networks of one or more communities and cultures they feel connected to. We suggest that this civic rather than 'ethno'-territorial understanding of diasporic networks has wider relevance for theorisations of diaspora, for studies of transnational mobility and knowledge transfer, and for university and public policies seeking to attract talent from abroad.
\end{abstract}

Key words transnational mobility; diaspora; knowledge networks; science; Germany; USA 


\section{Introduction}

Geographers have played an important role in theorising and exploring the closely linked concepts of transnational mobility and diaspora. They have especially helped to ground such research, stressing the importance of complexity, place, space, emotion, materiality, and historical perspective (e.g., Mitchell 1997; Ni Laoire 2003; Blunt 2007, Mavroudi 2007). Recent geographical scholarship has also displayed a growing uneasiness about essentialising and homogenising notions of diaspora as these are increasingly complicated by 'the proliferation of emigrant populations claiming belonging to two or more countries' (Ho 2011, 758). The aim of this article is to make a meaningful contribution to theorisations of transnational mobility and diaspora by systematically interrogating two research questions in the context of a globalising knowledge economy: Who belongs to a country's diaspora? And how can institutions and countries enrol individuals living abroad in mutually beneficial transnational knowledge networks?

Diaspora studies have traditionally been associated with the dispersal of unified groups of migrants linked together by shared ancestry, faith and/or national identities that have territorial roots and are often perceived as static and unchanging, especially by governments, policy-makers and institutions who wish to harness 'their' diasporas (Cohen 2008). These conceptualisations are based upon narrow and often exclusive notions of who 'counts' as part of a diasporic community because of how these concepts link diaspora with specific ethnicities, religions, nationalisms and territories that are often seen as primordial and 'given'. Recent geographical studies have thus stressed how diasporas are socially, culturally and materially constructed and constituted by identities that are dynamic and often 'in-between' (e.g., Blunt 2007; Mavroudi 2007). 
The first objective of this paper is to develop such flexible and inclusive conceptualisations of diaspora by stressing the importance of choice; by this we mean that notions of diaspora need to account for all those who choose to belong to a particular diaspora. To do this, we build on the work of Ancien et al. (2009) and their notion of 'affinity diaspora', meaning those people living abroad, who have ties to a specific cultural identity but who may have a different biographical history. More importantly, we develop the notion of an 'elective diaspora' in order to stress the power, right and liberty of individuals to choose whether they wish to be part of a diaspora and engage in the creation of diasporic networks. In similar ways as Savage et al. $(2005,29)$ introduced the idea of 'elective belonging' to community studies, we coin the term 'elective diaspora' to replace biologically and territorially-grounded concepts in the tradition of 'blood and soil' ideologies with culturally-defined understandings of social relations that emphasise the important role of emotional attachment and one's choice to participate in diasporic communities.

To demonstrate the value of this concept, we use a case study on knowledge diasporas. More specifically, we provide an empirically-grounded, theoretically-engaged and policy-relevant analysis of the role that US researchers with and without biographical connections to the German-speaking regions of central Europe have played for the proliferation of US-German knowledge networks since 1945. The analysis focuses on the testimony of visiting researchers from the United States, who were funded by the Alexander von Humboldt Foundation, a largely state-sponsored research agency re-established by the Federal Republic of Germany (FRG) in 1953 (Jansen 2004). After the allied defeat of the Nazi regime in 1945, the Humboldt mobility programmes aimed to re-integrate the country's universities and research institutes within a US-dominated world of science and scholarship through the various phases of the Cold War. The scientific collaborations and subsequent 
academic mobility that resulted from the interactions funded by the Humboldt schemes contributed significantly to a reunified Germany becoming the most important source country for international co-authors of journal articles written by US scientists and engineers from 2001 to 2005 (Jöns 2009).

The second objective of this article is therefore to add to recent debates about transnational academic mobility and collaboration by analysing the US researchers' motivations to spend a period of research leave of about one year in postwar Germany and possibly to engage in subsequent collaboration as well, despite the tragic legacy of the Nazi regime that sometimes affected the researchers' own family history. We argue that examining the pivotal role that US researchers with family and other socio-cultural connections to the German-speaking regions of central Europe have played for the multiplication of transatlantic knowledge networks since 1945 will expose the major limitations of ethno-territorial conceptualisations of diaspora and thus stress the relevance of elective diasporic communities as a notion that includes all those who wish to belong to particular diasporic networks and spaces. This underlines the need for policy makers to look beyond those they would traditionally regard as part of 'their' diaspora and prompts us to consider in the conclusions how viewing US-German knowledge networks through the conceptual lens of the elective diaspora could help to shape future policies on European diasporic and transnational knowledge networks.

\section{Transnational mobility and diasporic communities}

Our approach is informed by geographical and interdisciplinary debates about transnational mobility in the context of an emerging global knowledge economy and the cultural dynamics of diasporic communities as two main fields of research that have previously been analysed 
with only limited reference to each other. By linking these two lines of inquiry, we aim to advance overlapping debates in four ways. First, our research links interdisciplinary work on highly skilled and talent mobility (e.g., Smith and Favell 2006; Solimano 2008) to wider geographical debates on the closely related concepts of diaspora and transnational mobility (e.g., Blunt 2007; King 2012). While the former body of work emphasises circulations between home and host countries and has recently displayed an increasing interest in knowledge diasporas, with authors calling for more empirical case studies and suitable conceptual resources (e.g., Kuznetsov 2006; Fahey and Kenway 2010), the latter has devoted its main attention to homeland development and the conceptualisation of diasporas in other contexts than science and scholarship (e.g., Ní Laoire 2003; Larner 2007). We argue that bringing these two lines of research together helps to (re)conceptualise diaspora in flexible and non-essentialist ways (Mavroudi 2007; Ho 2011), to further our understanding of who belongs to a diaspora, and to clarify the conceptual bases of research on transnational mobility and knowledge networks.

Second, we see the need to develop more inclusive notions of both 'placebelongingness' and the 'politics of belonging', two concepts defined by Antonsich as 'feeling at home in a place' $(2010,646)$ and the 'discourses and practices of socio-spatial inclusion/exclusion' $(2010,649)$, in relation to both diaspora studies and highly skilled mobility. We feel that the proposed notion of 'elective diaspora' does this by focussing on people's emotional connections and feelings of belonging that constitute their diasporic identities and in turn have the capacity to shape the geographies of knowledge production and influence how policy-makers view (and potentially harness) diasporas, knowledge networks and mobile talent. 
Third, the analysis adds an historical perspective on transnational academic mobility, which centres on researchers and academics in universities (e.g., Bauder 2012), to work on highly skilled mobility that has mostly emphasised transnational circulations in high tech industries (e.g., Saxenian 2006) and advanced producer services (e.g., Beaverstock 2005). It also provides, as a fourth point, a novel geographical dimension to Anglophone academic debates about transnational academic mobility as these have focused either on historical perspectives from European countries and their empires (e.g., Heffernan 1994; Pietsch 2010; Meusburger and Schuch 2012; Heffernan and Jöns 2013) or on contemporary developments in Europe (e.g., Ackers and Gill 2008) and Asia Pacific (e.g., Welch and Zhang 2008; Leung 2013), thereby overlooking exchanges between Germany and the United States as the successive academic hegemons in the $19^{\text {th }}$ and $20^{\text {th }}$ centuries. The following sections outline how research on circular mobility, diasporic networks and knowledge diasporas frame our analysis and why we suggest the need to take into account the elective quality of diasporic belonging and networks.

\section{Circular mobility}

Recent geographical and interdisciplinary work on the global circulation of researchers and academics has analysed the patterns, motivations, experiences and outcomes of their participation in transnational academic mobility, with an emphasis on variations by historical and geographical context, duration, career stage, life cycle, gender, discipline and academic practice (e.g., Jöns 2007; Ackers and Gill 2008; Welch 2008; Bauder 2012). Whereas some studies have investigated academic career migration from one workplace to another (e.g., Pietsch 2010), the focus of this article is on circular academic mobility that is 
centred on a home institution or home country and often funded by public and philanthropic organisations (e.g., Heffernan 1994; Jöns 2009; Heffernan and Jöns 2013). Professionally-motivated circular mobility of researchers can be conceptualised as 'cycles of mobilisation' in Latourian 'centres of calculation' as each completed journey has a potentially accumulative effect on the point of origin, especially when a variety of material, social and intellectual resources mobilised en route is successfully used for the production of new knowledge claims back home (Latour 1987). As Jöns $(2009,318)$ argued that 'mobilization processes of scientists and scholars have been based not only on their own physical travel but also on correspondence networks and the circulation of others', knowledge centres 'have benefited from the expertise of visitors and from maintaining contacts at a distance'. Circular academic mobility, as studied in this article, can therefore 'be interpreted as a twofold mobilization process, involving the visiting academics and their [home] institutions as well as the hosting individuals and institutions' abroad (Jöns 2009, 318). From this perspective, it is evident that the centrality of knowledge centres with an external diaspora might more likely be reinforced than that of centres without such transnational linkages because researchers in diaspora might have additional incentives to visit places they feel connected to. In the context of postwar US-German exchanges, this raises the question how such a positive cumulative effect was possible given the historicallyburdened relationship between the two countries.

\section{Diasporic networks}

Since Mitchell (1997) encouraged geographers to locate concepts such as diaspora and hybridity both historically and geographically, geographical research has made significant contributions to diaspora studies (Ní Laoire 2003; Blunt 2007). Geographers have become 
especially interested in the economic, social and cultural benefits of diasporic networks that have shaped the emergence of a global knowledge economy and are increasingly mobilised by governments across the world as an important transnational resource (e.g., Larner 2007; Ho 2011; Gamlen 2012). Little research, however, has been done on how these transnational assets have impacted on knowledge production in science and higher education, including the role that biographical linkages across national and cultural boundaries have played for participation in academic mobility and the formation of transnational knowledge networks (Fahey and Kenway 2010).

Aiming to respond to this research desideratum, our understanding of diaspora builds on research that has challenged the traditional emphasis on defined, dispersed and displaced communities bound together by established nationalities, religions and ethnicities that centre upon a 'homeland' (Cohen 2008). Instead, this research aims to embrace more dynamic, process-orientated investigations of the negotiated, hybrid and multiple identities that shape the 'stances, projects, claims, idioms, (and) practices' (Brubaker 2005, 13) of diasporic networks characterised by complex notions of home and belonging. Drawing on Mavroudi (2007), we argue that conceptualising diaspora as a process, in which geographies of difference and similarity are negotiated in dynamic ways, helps not only to account for complex diasporic connections, flows and networks that create hybrid, 'diasporic spaces' (Brah 1996) across national borders but also for the often difficult and continuously evolving relationship between centre and dispersion. This is particularly evident in the context of USGerman relations as the loyalty of Jewish communities has traditionally centred on a text rather than a homeland (Clifford 1994, 326-27). Most of the Jews displaced from Nazi Germany were linked to multiple, real and imagined homelands due to their blended German-Jewish heritage and complex migration history. 
We strive to develop such a flexible notion of diaspora further by examining the contribution of a particular knowledge diaspora, namely diasporic researchers in the United States, to the development of US-German postwar academic relations. Implementing Ní Laoire's $(2003,279)$ approach that 'understanding diaspora practices and identities requires understanding their location in geographical, historical and material processes', we will be working towards a non-essentialist and more inclusive concept of diasporic identities, thereby accounting for 'a multiplicity of origins' (Ho 2011, 766) and diverse feelings of belonging that are difficult to capture with more conventional understandings of diaspora.

\section{Knowledge diasporas}

The terms 'knowledge diaspora', 'scientific diaspora', 'academic diaspora' and 'intellectual diaspora' are widely used but not well-defined concepts for knowledge workers, scientific researchers, university scholars across all disciplines, and a wider group of academics, writers, artists and others intellectuals, who are working abroad and share mostly 'ethno'national and/or religious ties with a home country. In an attempt to (re)conceptualize this phenomenon, we prioritize the term 'knowledge diaspora' as this captures diasporic networks in knowledge-intensive professions across high tech industries, advanced producer services and universities as the main sectors of the global knowledge economy.

At the core of the notion of the knowledge diaspora lies the dispersion of knowledge workers abroad; however, the role of group-based identities in the host country is contested. Some authors speak of a 'self-organised community of expatriate scientists and engineers working for the development of their home country or region, mainly in the areas of science, technology, and higher education' (Barre et al., 2003, 162), while others found that 'highly skilled expatriates do not have strong links with fellow nationals in host 
countries' (Meyer 2001, 100). Recent research by Ackers and Gill (2008, 148-149) supports the latter view, but it has also shown that diasporic '[c]onnections with scientists in their home countries ... play a very critical role' for reverse knowledge transfer and return moves. Accordingly, we suggest that researchers in diaspora are highly diverse groups of individuals, who are not necessarily defined by collective identities, but who may become linked with one another and a home country through individual feelings of belonging and shared experiences of socialisation such as language, cultural practices and education.

The few existing studies on knowledge diasporas in higher education and research, largely conducted in fields associated with geography, have mainly emphasised their contribution to homeland development in places such as Africa (e.g., Zeleza 2004) and China (e.g., Welch and Zhang 2008). A growing emphasis of the discussion is on diaspora strategies that aim to reconnect expatriates to their home countries through travel and communication in order to benefit from their expertise (e.g., Barre et al. 2003; Hugo 2005; Kuznetsov 2006). When advising the Scottish Government on the design of a diaspora strategy, geographers have recently developed the idea of an 'affinity diaspora' (Ancien et al. 2009). We wish to introduce this concept into academic debates as it stresses the need to widen the outlook of policy discourses on who belongs to a diaspora with the twofold aim of avoiding a 'racialisation of economic policy and national growth strategies' (Ancien et al. 2009,12 ) and targeting as many relevant constituencies as possible with limited resources:

An affinity diaspora is a collection of people, usually former immigrants and tourists or business travellers, who have a different national or ethnic identity to a nation state but who feel some special affinity or affection for 
that nation state and who act on its behalf, whilst resident in the state, after

they return home, or from a third country (Ancien et al. 2009, 14).

This notion of an affinity diaspora is inspired by Tsagarousianou's (2004) argument that diasporas do not only imply the transnational but are also increasingly transient in nature due to improved transportation and communication technologies. Her definition of diaspora can be usefully adopted for knowledge diasporas as these, too, refer 'to complex multidirectional flows of human beings, ideas, products - cultural and physical and to forms of interaction, negotiation and exchange, processes of acculturation and cultural creativity, webs of exclusion and struggles to overcome it' (Tsagarousianou 2004, 64). For Ancien et al. $(2009,13)$ this means 'that not all expatriates are diasporeans, the term being confined to those who are proactively engaged in transnational activity.'

Building on these considerations, we argue that knowledge diasporas can be based on emotional ties to a home country through birth and ancestry and/or other socio-cultural linkages, including citizenship and religion, that involve some degree of emotional attachment to a specific place, community or culture. Such diasporic networks are always practice-based and can form either between diasporic researchers abroad or with colleagues in the diasporic home country. Their constitutive professional and emotional ties are part of an individual's web of biographical connections by which we mean those aspects in the history of a person's life that link this individual to a specific place or culture, such as family relations, educational/work experience, migration, travel, cultural interests, friendship and love. As biographical connections can exist without an individual's engagement in diasporic networks, we propose acknowledging the pivotal role that choice 
plays in one's decision to participate in the creation of diasporic linkages by introducing the notion of the 'elective diaspora'.

We define the elective diaspora of knowledge workers as a practice-based, flexible association of highly diverse professionals and other talent, who might not be in contact with each other, but who have formed emotional ties with a particular place or culture and chosen to participate in the construction of diasporic knowledge networks. This concept differs from existing notions in three ways. First, it shifts the focus from defining 'ethno'territorial linkages to emotional ties based on a variety of biographical connections to people, places, communities and cultures; ${ }^{i}$ second, it stresses the possibility that individuals can choose whether they wish to support diasporic networks of a place or culture they feel connected to; and third, it implies a conscious decision to associate oneself with a given community beyond performative reasons for at least a semi-permanent period of time.

Before developing the idea of elective diasporas based on an in-depth analysis of the role that biographical connections of visiting researchers from the United States in Germany played for the proliferation of US-German knowledge networks since 1945, we wish to highlight that stressing the emotional dimension of diasporic linkages creates a difference between transnational and diasporic knowledge networks. Transnational knowledge networks can purely be motivated by professional reasons and epistemic interests, thus constituting 'epistemic communities' (Haas 1992). Diasporic knowledge networks contribute to both transnational knowledge networks and epistemic communities but are also constituted by feelings of cultural belonging that may encourage professional circulations between home and host countries. Accordingly, the elective diaspora of knowledge workers goes beyond the very practices of knowledge production and dissemination by involving a range of socially, culturally and politically motivated associations. 


\section{Research methodology}

Drawing on diaspora and mobility studies requires a flexible usage of the terms "home country' and 'host country' as these expressions have acquired very different connotations in these two fields of research (Fahey and Kenway 2010, 568). From the perspective of diaspora studies, Germans in the United States can be linked to Germany as their 'homeland' (Heimatland), but when they participate as researchers in circular academic mobility, their country of work, the United States, would be seen as their home country (Herkunftsland), while Germany becomes the host country (Gastland) for the period of their research leave. Therefore, we define US researchers as all those who have worked in a US institution for a certain number of years, thus being eligible for different types of German research funding, whose aim is to support foreign researchers. These US researchers can have different nationalities and types of biographical connections to German language and culture so that our analysis will examine the extent and nature of such relations.

The study is based on original qualitative and quantitative research conducted in two subsequent research projects. These projects aimed at examining the motivations, experiences, immediate outcomes and long-term effects of research visits by post-docs and established researchers from different countries at universities and research institutions in the FRG. These research visits have been facilitated by the Humboldt Foundation in the context of their two main funding schemes, research fellowships and research awards (Jansen 2004). This article provides the first analysis that focuses on the perspective of visiting researchers from the United States in both schemes and across all disciplines, thus covering experiences at different career stages over several decades.

The analysis draws on 82 semi-structured interviews of 30 minutes to two hours, which were conducted in the United States with 61 US research awardees from 1972 to 
1996 (cited as PRT) and with 21 research fellows, who had come to Germany from various countries in the period 1963 to 1997 but worked in the United States in 2003 (cited as STP). The interview data is complemented by anonymised statistical data provided by the Humboldt Foundation on both funding schemes and by two postal surveys, a total survey of all 1,719 US research awardees from 1972 to 1996 (response rate: 65 per cent) and a sample survey among Humboldt research fellows from all countries of origin (i.e., country of workplace, not of citizenship). The sample survey targeted every fifth former visiting researcher from 1954 to 2001 and generated 1,893 questionnaires (response rate: 51 per cent), of which 172 were US research fellows in Germany from 1954 to 2000.

The unique long-term perspective of this article emphasises academic mobility to West Germany prior to re-unification in 1990. Even if the Humboldt programmes were extended to eastern German institutions after re-unification, universities outside of Berlin received few Humboldt visiting researchers before the year 2000 as new research infrastructure and wider international networks were still being formed (Jöns 2002). Our main period of interest also predates the rise of email as an important vehicle for scientific collaboration, which means that research visits were often vital for conducting international projects.

Three key questions inform the following analysis: What kind of biographical ties did visiting researchers from the United States possess in Germany and how did these influence their academic interactions? Why did US researchers with and without biographical ties to Germany contribute to the construction of US-German knowledge networks? And what do these inquiries suggest for our understanding of diasporas and their role in shaping the geographies of the global knowledge economy? 


\section{Creating new allies? Humboldt visiting researchers from the United States}

The geopolitical divisions of the Cold War provided the context in which the re-building of Germany's shattered infrastructure became possible after 1945 and was generously assisted by the allied powers - in the democratic FRG to the west of the Iron Curtain more so than in the communist German Democratic Republic (GDR) to its east (Heffernan 2007). German universities, epitomizing the pinnacle of global science and scholarship in the $19^{\text {th }}$ and early $20^{\text {th }}$ centuries, initially faced similar challenges in the two separate states as they had been deprived of most of their intellectual elite through the dismissal of mainly Jewish academics after 1933. Of those Jewish scientists and scholars, who were able to escape the Holocaust through emigration, almost 90 per cent settled in the United States (Krohn et al. 1998, 683).

The process of restoring international academic relations in the FRG began with exchanges organised by the allied powers and with lecture tours by prominent visiting academics, who were often returning emigrant scientists and scholars (Krauss 2006). This process culminated in the early 1950s with the re-establishment of federal organisations such as the German Academic Exchange Service (Littmann 1996). The Humboldt Foundation, re-established in December 1953 to support academic studies of international researchers in West Germany (Jansen 2004), was particularly well-suited for repairing the damaged image abroad as its eponym, the renowned naturalist Alexander von Humboldt, was widely regarded as 'a cosmopolitan scientist who represented the admirable part of German culture, that of universal learning, non-militaristic and non-nationalistic' (Rupke 2005, 141).

The Humboldt research fellowship programme began in the academic year 1954-55. Initially supporting doctoral students as well, the programme has focused on post-docs and established researchers since the early 1970s, when enormous state investment in research and development began to attract a growing number of visiting scholars from leading 
scientific nations such as the United States (Figure 1A). These US research fellows were mainly post-docs and professors at an early career stage with an average age of thirty-four years (1954-2000). Their disciplinary profile emphasised the humanities in the 1950s (57 per cent) and was dominated by the natural and engineering sciences in the 1980 s (68 per cent).

[Figure 1 about here]

In 1972, the Humboldt Foundation established their prestigious research awards in order to invite US scientists with past achievements for a period of research leave to Germany. Designed as one of several measures to thank the United States for their Marshall Plan Aid, the scheme was announced by German chancellor Willy Brandt at Harvard University on 5 June 1972, exactly 25 years after US foreign secretary of state George Marshall had introduced there his plans for supporting the reconstruction of Europe (Jöns 2003). An important symbol of loyalty to the United States during Brandt's new Ostpolitik, the US senior scientist programme, as it was known before its extension to all disciplines and countries in the early 1980s, supported distinguished US professors at an average age of fifty-two years (1972-1996; Figure 1B). The great majority of these research awardees were natural scientists and engineers, thus reflecting the economic significance of these fields.

Both Humboldt schemes were more attractive for German-born researchers than for researchers born in the United States and elsewhere. Among the highly prolific US research awardees, who included many Nobel Prize winners, ten per cent were born in Germany (1972-1996), which resulted in ten times more US awardees being German-born (19871996: 7.4 per cent) than among science and engineering faculty at US universities (NSB 1998). This share of German-born researchers was three times higher than among research 
fellows, which shows that the existence of biographical connections to Germany was most important for attracting senior US professors for extended periods of research leave. This was especially true in the 1970s, when science and scholarship at the leading US research universities was in most disciplines intellectually far ahead of related academic discourses in Germany so that cultural linkages were able to substitute for lacking academic incentives (Jöns 2003). For researchers at earlier career stages, Humboldt funding provided an opportunity to generate positive feedback effects for their own career and research group so that their research visits were less motivated by cultural reasons (Jöns 2007).

The following sub-sections elaborate how the funding schemes of the Humboldt Foundation for visiting researchers in Germany drew disproportionately on a looselydefined US-based knowledge diaspora by discussing the experiences of three groups of US researchers: those who had biographical ties to the German-speaking regions of central Europe through birth and ancestry; those who had biographical connections based on other family relations, partnerships, friendships, work/living experiences, language skills and cultural knowledge; and those who had no prior biographical linkages but might have been drawn into US-German knowledge networks whilst in the country. The analysis uses these case study examples for outlining five conceptual contributions of the elective diaspora to theorisations of diaspora and transnational knowledge networks.

\section{(Re)connecting with the homeland?}

Among the US senior scientists interviewed, every third researcher was linked to the German-speaking regions of central Europe via birth and ancestry. This included members of the Jewish diaspora, who had lived in German-speaking countries, or territories occupied by the German Reich, and had experienced the traumatic dispersal from Nazi Germany 
themselves. These first generation displaced migrants returned to postwar Germany as Humboldt scholars despite their often horrific personal experiences and ambiguous feelings towards the country. The recollection by an Austrian-born US scientist, who stayed in Germany for twelve months in 1983-84, is particularly moving and explains why it was possible to revive US-German academic exchanges despite the enduring impact of the Holocaust and other Nazi crimes on individual lives:

I came to the United States in 1940 ... I'm Jewish and so it's clear that I came here because in fact I had to. We waited that long because I came from a family that was very heavily involved in the Austrian army ${ }^{\mathrm{ii}}$... in fact, my father was wounded twice, and so it was very difficult for my father, unfortunately, to realise how urgent it was to leave. (PRT-51, engineering, 1983, twelve months)

As the father of this US scientist was born in Poland, when the scientist's grandfather was stationed in what was then a part of Austria, he did not get a visa into the United States because there were quotas by place of birth not nationality, and the Polish quota was very small. After waiting until the spring of 1940, the US scientist, a teenager at the time, his mother and two grandmothers immigrated to the United States, while his father decided to escape through Yugoslavia, where he had served in WWI:

[He] led a number of people across the border. He spoke the language of Serb-Croatian, and he knew the geography ... and because of his language skills he began to work for the Red Cross there. Then the German army 
marched through Yugoslavia ... I mean he escaped in April of 1940 and in April 1941 the Germans invaded Yugoslavia, and so he was caught again. We still heard from him until the middle of 1941, mostly through cards sent by the Red Cross, because he was still working for [them], and that was the last we heard of him. (PRT-51, engineering, 1983, twelve months)

The mother of this US research awardee never spoke a word of German again, while he himself volunteered for the US army, fighting in France towards the end of the war and trying to find his father. He named three reasons for why he later established close scientific contacts in Germany and lived there for a year. First, he learned to differentiate between 'guilt' and 'responsibility'. The current generation of Germans and the postwar generation would not be guilty, but this would not free them from the responsibility of making sure that the Nazi period remains alive in public consciousness and will never happen again. Second, he thought that in contrast to Austria and France, Germany had confronted its Nazi past in a serious manner, which paved the way for normal interaction; and third, he regarded the Humboldt Foundation as a perfect vehicle for the idea that we all live on this one planet and thus should better get along well with each other.

This US researcher valued the Humboldt Foundation so much that he became the founding president of the US Humboldt club, an alumni organisation for Humboldt scholars. His example thus underlines the institution's invaluable contribution to enthusing even those emigrant researchers in the United States about US-German knowledge networks, who would have had every reason to stay away from them. The researcher's elaborate explanation of why he supported US-German knowledge networks also exemplifies why we see the need to stress the 'elective' quality of diasporas. As an Austrian-born scientist, he 
did not join an unproblematic affinity diaspora based on cultural heritage and nostalgic childhood memories. On the contrary, this researcher consciously differentiated between Austria and Germany, arguing that he devoted his time to collaborations in Germany as this country had dealt with the past in a manner that enabled him to engage - in his opinion, this did not apply to Austria where he was born and spend most of his childhood years.

In conceptual terms, this example helps to illustrate why the concept of elective diasporic identities critiques existing notions that contain vestiges of an 'ethno'-territoriality and instead prioritises people's 'routes' over 'roots' (Gilroy 1993) when explaining why researchers get involved in transnational knowledge networks (first conceptual contribution). For instance, the idea of a homeland-centred diaspora that implies 'a common sense of territorial identity among its members' (Dahlman 2004, 486) could never easily be projected on Germany's complex territorial history. Before the formation of the first German nation state in 1871 , when the territorial mosaic of microstates did not even allow for the designation of a territorially-fixed homeland, associations with a geographically-dispersed and differentiated German culture were seen as the uniting feature of a German diaspora (Hoerder 2002). Building upon Immanuel Kant's ideal of a cosmopolitan European order, this resonates with contemporary ideas about the separation of a de-territorialised 'culture-state' and a territorialised 'nation-state' as 'the only secure defense against the dangers of nationalism' (Pagden 2002, 21). Accordingly, Germanspeaking researchers from Austria and other European countries can also be regarded as part of the loosely-defined US-based knowledge diaspora that helped to (re)create USGerman knowledge networks after 1945 as their biographical history and affinity to German language and culture provided an additional incentive to (re)visit mainland Europe for an extended period of time. 
Other researchers had been born in Germany and voluntarily immigrated to the United States, mostly after WWII, when a new 'brain drain' saw thousands of German students and academics leave their home country to seek education and employment elsewhere (Ash 2004). These first generation migrants by choice often engaged in diasporic knowledge networks because they were grateful for the support they had received from public institutions and not because they were nationalistically-minded:

I received all my education in Germany and left for the United States just when I had finished my Habilitation ${ }^{i i i}$ [in 1983]. I am not quite sure how much my education had cost Germany and thus I feel this responsibility to do something for [this country]. This is why I am surely more active in my connections to Germany than the ordinary US scientist. (PRT-30, physics, 1994, eleven months)

The motivation of this physicist to keep in close contact with his former alma mater and other institutions in Germany also had straightforward academic reasons as he benefitted from a constant influx of highly-qualified graduate students and post-docs. In turn, his German guests gained advanced research training and valuable contacts in a leading US research university, which often helped them to get permanent positions in Germany or the United States. This physicist had originally left Germany because of the contracting academic labour market in the early 1980s, first for a temporary post in Sweden and then for a permanent job in the United States, but by maintaining his academic links, mainly through German funding schemes for circular academic mobility, he turned a classical brain 
drain situation into a US-German win-win-situation involving several individuals and institutions in both home and host country.

Those second and third generation Germans (and beyond), whose ancestors or parents had migrated to the United States since the large immigration waves in the late $19^{\text {th }}$ century (if not before), mostly displayed a greater emotional distance to German culture but were often still curious about their family heritage. Some of these researchers actively traced their German ancestors in the country, while others had visited relatives before:

My parents were German. They'd immigrated before the war, but after the war I spent a number of summers visiting relatives in Germany. As a teenager I had worked for a summer in Germany and I'd spent a year at the [Swiss Federal Institute of Technology] in Zurich. (PRT-6, physics, 1986, nine months)

This particular physicist stressed that his period of research leave in Germany helped him to bring European contact to his US laboratory. He transferred his scientific contacts to one of his former students, a professor at a leading US research university, who became a Humboldt scholar himself, and he was also very pleased that his two teenage boys enjoyed their stay in Germany, subsequently learned German in school and went back to visit.

In all three examples of US researchers with family ties to the German-speaking regions of central Europe (PRT-51, PRT-30, PRT-6), the Humboldt schemes helped to mobilise US-German diasporic networks for intensifying knowledge networks between the two countries. This is confirmed by the long-term effects of both Humboldt schemes, as German-born US researchers were pivotal for generating subsequent flows of students, 
post-docs and professors. German-born US researchers also initiated more academic events with colleagues in Germany, published more research results in German-language journals and books and served more often as referees for students and researchers from Germany than their colleagues born in the United States and other world regions (Table I). ${ }^{\text {iv }}$

[Table I about here]

This creation of a circulatory form of 'chain migration' or 'brain circulation' through diasporic communities has also been observed in other segments of the global knowledge economy, notably in Saxenian's (2006) work on the 'new argonauts'. By pointing out how US educated immigrant scientists and engineers working in Silicon Valley shaped the growth of new centres of technology entrepreneurship in formerly peripheral economies such as India, China and Taiwan by taking advantage of new economic opportunities in their home countries, Saxenian (2006) depicted a twofold mobilization process between established and emerging 'centres of calculation' with similar cumulative effects as discussed in this article for US-German knowledge networks. In both cases, diasporic networks of USeducated immigrants reinforced the central status of knowledge hubs in home and host countries through frequent circulatory movements, but in this case study, other than migration-related biographical ties were also crucial for fostering such intense exchanges.

Mobilising the diaspora beyond birth and ancestry

Every sixth of the interviewed US senior scientists mentioned biographical ties to central Europe apart from birth and ancestry that also encouraged diasporic linkages. Most of these 
researchers had a partner of German origin, which often led to close cultural proximity and personal ties:

My family came with me, yes, one of my daughters ... studied in Germany ... She learnt German when she was born. My wife is German. She has been back very often, every summer. So yes of course it was a very good experience to have [an] extended [stay] not just two or three months but a whole year to be in Germany ... My father in law [still lives there]. (PRT-46, bio sciences, 1991, twelve months)

A partner from Germany often paved the way for extended periods of research leave through his or her distinct interest in visiting family and friends and the fact that bilingual children can enter any school in the host country. Other US researchers had relatives or friends living in Germany, which also encouraged extended periods of research leave:

It was a combination of many things. I like music and art and of course Munich is a wonderful place for that. I like science and a number of people in or near my area of research ... were in Germany, so that was stimulating. Another reason was family, if I was to spend a sabbatical, for my [Dutch] wife it would be nice to be near her sister, and so that was also a consideration. (PRT-33, chemistry, 1980, twelve months)

These two examples of US researchers' emotional ties to people living in the host country help to point out that the concept of the elective diaspora puts the emotional attachment to 
people, places, communities and cultures at centre stage (second conceptual contribution). It favours a flexible and territorially-unbounded notion of diaspora because feelings of belonging to certain places may change when the people who are at the centre of this attachment move elsewhere. If we bring to the fore the importance of emotional ties that have recently been stressed by geographers in the context of the 'affective turn' (e.g., Pile 2010), we can include those individuals who would not traditionally be seen as part of the diaspora because they may not possess 'ethno'-national ties, but who nonetheless feel connected in other socio-cultural ways, thus constituting an equally important transnational asset - what Ancien et al. (2009) called 'affinity diaspora'.

Strong friendships between the visiting researchers and their academic hosts, who had sometimes known each other since they were PhD students or post-docs, also emerged or intensified during the research visit, through collaboration on an everyday basis and joint activities in the evenings and over the weekend. Friendships were even able to compensate for traumatic experiences from the Nazi period and thus helped to overcome barriers to academic mobility. A Dutch physicist, who still suffered from nightmares 60 years after he had lost many relatives in Auschwitz and other concentration camps, explained the close collaboration with his Humboldt host for over 20 years with the simple statement:

He was my friend and not responsible for the crimes committed by the Nazis. (PRT-3, physicist, 1985, twelve months)

Mutual trust, sympathy and shared experiences of visiting researchers and their hosts often paved the way for productive intellectual exchanges and long-term collaborations. This is in many ways comparable to the role that pre-emigration friendships played for the formation 
of a Soviet academic diaspora (Isaakyan 2010) and thus stresses the importance of friendship for creating transnational knowledge networks. However, as the example of the Dutch visiting researcher shows, the affinity he felt was very much focused on an individual scientific friend, especially as he made every effort to clarify that he would not be willing to help the German economy in any way. Other members of the Jewish diaspora in the United States could not be convinced to spend a research leave in Germany and did also not understand why their Jewish friends could accept a Humboldt research award or fellowship. We therefore argue that it is essential to stress the 'elective' nature of the US researchers' scientific collaborations in Germany to avoid the impression of a simplistic and largely performative affinity diaspora.

The notion of elective diasporic linkages thus acknowledges that not all researchers with family ties to another country wish to be part of its knowledge diaspora (third conceptual contribution). Fahey and Kenway (2010, 567-568), for example, have argued that policy discourses on the mobilisation of expatriate communities for the benefit of the home nation tend to be 'blind to the fact that the manner in which "home" is perceived' may have changed, creating either a 'polycentric view of home' or mixed feelings due to adverse conditions that had caused emigration in the first place. Placing a cosmopolitan respect for 'the dignity of reason and moral choice in every human being' (Nussbaum 1997, 59) at the centre of the elective diaspora thus adds to the flexibility and usefulness of this concept.

Other US researchers had previously lived in Germany and either spent part of their education at German schools and universities or worked there:

I actually went to High School for a year in Germany, because my father was a professor at the University in Munich, and then I had post docs from 
Germany, ... so that's basically how I ended up [at my host university], because he went back to Germany. (PRT-29, bio sciences, 1995, six months)

Some of these researchers also had other biographical ties to Germany prior to their first period of Humboldt research leave, such as the cited bio scientist, whose sister was still living in Munich. His educational experience in Germany might have contributed to him taking on more post-docs from Germany than from other countries, but scientific reasons, such as an on-going project of his former post-doc, strongly encouraged his research visit. The elective diaspora therefore remains a flexible concept centring on emotional ties based on socio-cultural affinities, whose specific role for transnational academic mobility is, however, difficult to specify in all cases.

Finally, cultural affinities with the host country based on language skills, cultural knowledge and feelings of belonging intensified the researchers' interest in Germany. The affective dimension was sometimes clearly more important for their choice of research leave destination than scientific incentives, especially in the earlier postwar decades:

Well, England seemed just not enough different ... and France, I don't know any French and I just don't feel as at home there, and Germany just seemed interesting and attractive, and I like Germany. ... Yes, I think if it had been a purely scientific decision, it's not clear that I would have done that. (PRT-41, chemistry, 1981, twelve months, commenting on his first research visit to Germany as a NATO postdoctoral fellow, 1967, twelve months) 
This researcher's attachment to Germany was not linked to shared ancestry or family and friends and thus helps to clarify why the concept of the elective diaspora draws on Clifford's $(1994,306)$ critique of too much focus in diaspora studies on homeland orientation and 'a teleology of origin/return' in order to substitute the conventionally defining criteria of 'ethno'-territorial linkages based on birth and ancestry, or ethnicity and nationality, with a range of biographically-contextualised emotional ties to communities or cultures in which one feels at home (fourth conceptual contribution). By so doing, the proposed concept resonates in many ways with the idea of 'elective belonging' that Savage et al. $(2005,29)$ introduced to community studies to break with the conception that local social relations are defined by 'those "born and bred" in an area'. Elective belonging 'articulates senses of spatial attachment, social position, and forms of connectivity to other places' (Savage et al. $2005,29)$ when people are able to link these places, communities or cultures to their biographical life history and thus feel they belong there. In similar ways, the notion of elective diasporic identities focuses on the ties that really matter for feelings of belonging, or how Antonsich (2010: 647) put it, 'for feeling "at home" and "safe"'.

\section{Enrolling new allies?}

As every second interviewed US senior scientist had some kind of biographical connection to German-speaking central Europe prior to their first period of Humboldt research leave, the other half of researchers was mainly motivated by academic reasons to spend about a year of their life in Germany. This other half of US researchers included first, new diasporic allies, who became part of the elective diaspora through their academic collaborations and new personal contacts; second, new academic allies, who maintained academic exchanges for professional reasons for at least some time without developing a comparable emotional 
attachment; and third, those one-time visitors, who had neither a particular association with Germany prior to their first period of Humboldt research leave nor had any reason to return for an extended period afterwards. The Humboldt schemes thus frequently helped to recruit new allies for maintaining transatlantic knowledge networks, even among those US researchers, who were born outside Europe and had no previous private or academic contacts in Germany; however, these were fewer instances and often resulted in shorter subsequent interactions (Table II).

[Table II about here]

Diasporic knowledge networks thus need to be seen as part of wider transnational knowledge networks that are professionally-motivated but might much more easily shift in scale and geographical location without the additional emotional ties that bind diasporic researchers to specific places, communities or cultures. Long-term associations often followed when visiting researchers without prior biographical connections to Germany met their future partner during their period of research leave in that country:

I developed some very nice contacts, including with my current husband, that's how we met ... I was going to leave, it was at the end of my Humboldt ... when he got a position in [my host university] ... we just happened to meet at somebody else's place. (STP-18, bio sciences, 1979, 24 months)

Conceptually, the notion of an elective diaspora thus opens up the possibility that visiting researchers without prior personal and cultural connections to their host country may 
develop such linkages during their stay and may therefore feel connected to several knowledge diasporas at the same time (fifth conceptual contribution). They may either decide to continue interactions with colleagues and friends in Germany afterwards or become part of the talent reserve abroad that may be mobilised for future international collaborations because of existing socio-cultural ties (Meyer 2001). The concept of the elective diaspora therefore acknowledges that feelings of home may neither be tied to a former home nor to a territorial constituency but may include 'a plurality of places, institutions and epistemic communities' (Fahey and Kenway 2010, 568).

Those researchers, who did not continue any collaboration after their research leave in Germany, may not have developed close linkages or may connect more to other cultural contexts. Accordingly, many of the visiting US researchers without prior biographical links to Germany had previous academic contacts as part of their wider epistemic communities but were pulled towards the country by the strong interest of their hosts:

[My academic host and I] had slight contacts now and then ... [He] was interested in establishing [the technique we had developed here] in his laboratory and he'd been talking to me from time to time about the possibility of my visiting there. (PRT-47, physics, 1991, seven months)

This chemist had in turn an interest in the German group's compounds so that he collaborated with his hosts on measurements and the writing up of results over a period of three to four years, but then both groups refocused on previous collaborations with more overlap in their research. For those visiting US researchers, who did not develop any emotionally-loaded biographical connections to Germany before or during their research 
visit, the Humboldt schemes typically strengthened transatlantic interactions for only a limited period of time.

Occasionally, the interest of the academic hosts in getting help with their research was so one-sided that the academic guests found it difficult to recall a specific benefit for themselves, even if the interaction, as in the following case, resulted in a joint publication:

It is hard to say... I think the main thing ... was not so much the learning but the intellectual stimulation. Being there, having people coming by, very excited, wanting to talk to you ... This was certainly one of the sparks that really kept my enthusiasm. (PRT-52, mathematics, 1984, nine months)

This researcher did not decide to continue academic collaborations in Germany despite of the nine months he spent in the country. His example therefore underlines the conceptual value of elective diasporic linkages prioritising the ability of people to choose whether they wish to be actively connected to places, communities or cultures they encountered. The elective nature of diasporas implies a conscious decision to associate oneself with a diasporic community for longer periods of time than the performative participation in German beer festivals, Christmas markets and other cultural events would imply, while at the same time stressing that individuals would be free to join and leave these diasporic networks whenever they wished, irrespective of their ethnicity, nationality and location.

\section{Conclusions}

This article has developed the notion of elective diasporic communities, identities and belonging as a response to recent calls by geographers for alternative conceptual resources 
that overcome prevalent ideas of 'ethno'-territorial, national and faith essentialisms in conventional understandings of diaspora (e.g., Mavroudi 2007; Ho 2011). Our case study has examined the role of a specific knowledge diaspora, namely visiting researchers from the United States in the Federal Republic of Germany (FRG), for the proliferation of US-German knowledge networks since 1945. Our study makes three main contributions to the growing bodies of geographical and interdisciplinary work on transnational mobility and diaspora that usefully frame discussions about diasporic knowledge networks (Kuznetsov 2006).

Empirically, we have shown how the funding schemes of the Humboldt Foundation for visiting researchers in Germany drew disproportionately on a loosely-defined US-based knowledge diaspora with a range of biographical ties to the German-speaking regions of central Europe. These ties resulted from birth and ancestry as well as from other family relations, partnerships, friendships, work/living experiences, language skills and cultural knowledge. They either provided an additional motivation for a period of research leave in Germany or developed during this time. By paving the way for mutual understanding and cultural proximity, biographical linkages facilitated the exchange of tacit knowledge, compensated for some of the visiting researchers' traumatic experiences from the Nazi period, and often shaped diasporic identities to such an extent that the US researchers participated in the construction of US-German knowledge networks for a long time.

US researchers with biographical ties to Germany were more likely to generate subsequent academic mobility and collaboration than their colleagues without such connections and thus contributed significantly to the cumulative process that has linked scientific research in Germany and the United States ever more closely since the 1970s (Jöns 2009). The proliferation of US-German knowledge networks since 1945 thus partly underlines the historical specificity of a postwar relationship that could build on existing 
biographical ties due to previous migrations to the United States, but it also underlines how funding schemes for incoming and outgoing academic mobility can help to enrol new allies in transnational knowledge networks and to (re)produce a country's diaspora.

Conceptually, we have proposed the notion of elective diasporic communities to advance academic debates that criticise essentialist and homogenising understandings of diaspora (e.g., Fahey and Kenway 2010; Ho 2011). Drawing on recent work in diaspora and mobility studies, we define elective diasporas in the context of the knowledge economy as practice-based, flexible associations of highly diverse individuals, who might not be in contact with each other, but who may have formed emotional ties with a particular community or culture and chosen to participate in the construction of diasporic knowledge networks. This civic rather than 'ethno'-territorial notion builds on the idea of affinity diaspora (Ancien et al. 2009) by acknowledging that diasporic communities are flexible and complex social and cultural formations, but it emphasises in similar ways as the concept of elective belonging (Savage et al. 2005) that diasporas comprise those who choose to associate themselves with a given community or culture, albeit beyond the fleeting moment of performative events (e.g., participation in cultural festivals and holidays).

Such an inclusive concept of diaspora further develops Mavroudi's (2007) conceptualisation of 'diaspora as process' as it allows for a more diverse, unbounded and complex understanding of dynamic, practice-based diasporic knowledge networks. It responds to the article's first research question who belongs to a country's diaspora in five ways, namely by critiquing 'ethno'-territorial delineations; by stressing the pivotal role of emotional attachment; by allowing for a wide range of biographically-contextualised emotional ties; and by acknowledging that not all biographically-connected individuals wish to be part of a country's diaspora, whilst others may feel connected to more than one 
diasporic community. Future studies of diaspora could investigate to what extent this concept would be useful in other realms of society than knowledge production, whereas scholars working on knowledge-related transnational mobility should more often consider those emotional ties that link people, places, communities of practice and epistemic cultures together, thus shaping career trajectories and the global circulation of knowledge.

Finally, in regard to the second conceptual key question raised in the introduction, we argue that the concept of an elective knowledge diaspora carries wider implications for policy and practice in those cultural contexts that either have benefitted or could benefit from mobilising diasporic networks for mutually beneficial transnational knowledge networks (e.g., Larner 2007). This applies especially to Europe, where global family linkages have been decreasing for historical reasons since the large emigration waves in the late $19^{\text {th }}$ century (US Census Bureau 2013). For example, a relatively high share of 4.4 per cent of German-born Americans in 1890 had declined to only 0.3 per cent by 1990 (Henning 1999). Policy makers in Britain, France, Germany and other European countries need to be aware that these long-term changes in the composition of global diasporas are being reinforced by global flows of incoming and outgoing international students, researchers and academics shifting towards Asia Pacific (Jöns and Hoyler 2013). These two trends have begun to impact on regressive sponsorship figures in Germany (Figure 1B; Jöns 2003) and affect European diasporic networks in the United States more generally (US Census Bureau 2013). In the future, European governments could nurture their global diasporic communities by substituting eroding diasporic linkages based on birth and ancestry with the creation of alternative socio-cultural ties (Kuznetsov 2006; Ancien et al. 2009). We argue, however, that policy makers and practitioners also need to be conscious of the elective nature of diasporic identities as this means that the loyalty and multiplier effect of 
individuals living abroad, who share a sense of belonging to a specific cultural context, cannot be taken for granted. In this regard, the case study of the Humboldt mobility programmes may sketch a sustainable way forward as this has shown how the provision of attractive funding schemes for research can help to mobilise both existing and new allies for generating cumulative effects of transnational mobility and knowledge network formation.

\section{Acknowledgements}

This article is based on research funded by the German Academic Exchange Service and the German Research Foundation. Special thanks go to the editor Gavin Bridge and three anonymous referees for their valuable suggestions on producing this final version. We dedicate this article to George Leitmann, Professor Emeritus of Engineering Science in the University of California at Berkeley, to express our deep respect and admiration for his significant contributions to peace and science in Germany over the past seven decades.

\section{References}

Ackers L and Gill B 2008 Moving people and knowledge: scientific mobility in an enlarging European Union Cheltenham: Edward Elgar

Ancien D, Boyle M and Kitchin R 2009 The Scottish diaspora and diaspora strategy: insights and lessons from Ireland Crowne Publishers, Edinburgh

Antonsich M 2010 Searching for belonging: an analytical framework Geography Compass 4 644-59

Ash MG 2004 Science and scientific exchange in the German-American relationship in Junker D ed The United States and Germany in the era of the Cold War 1945-68: A handbook: Volume 1 Cambridge University Press, Cambridge 417-24 
Barré R, Hernandez V, Meyer J-B and Vinck D 2003 Scientific diasporas: how can developing countries benefit from their expatriate scientists and engineers? Institut de Recherche pour le Développement, Paris

Bauder H 2012 The international mobility of academics: a labour market perspective International Migration DOI: 10.1111/j.1468-2435.2012.00783.x

Beaverstock JV 2005 Transnational elites in the city: British highly-skilled inter-company transferees in New York City's financial district Journal of Ethnic and Migration Studies $31245-68$

Blunt A 2007 Cultural geographies of migration: mobility, transnationality and diaspora Progress in Human Geography 31 684-94

Brah A 1996 Cartographies of diaspora Routledge, London

Brubaker R 2005 The 'diaspora' diaspora Ethnic and Racial Studies 28 1-19

Clifford J 1994 Diasporas Cultural Anthropology 9 302-38

Cohen R 2008 Global diasporas $2^{\text {nd }}$ edition Routledge, London

Dahlman C 2004 Diaspora in Duncan J, Johnson N and Schein R eds A companion to cultural geography Blackwell, Oxford 485-98

Fahey J and Kenway J 2010 International academic mobility: problematic and possible paradigms Discourse: Studies in the Cultural Politics of Education 31 563-75

Gamlen A 2013 Creating and destroying diaspora strategies: New Zealand's emigration policies re-examined Transactions of the Institute of British Geographers 38 238-53

Gilroy P 1993 The Black Atlantic: modernity and double consciousness Routledge, London

Haas P 1992 Introduction: epistemic communities and international policy coordination International Organization 46 1-35 
Heffernan M 1994 A state scholarship: the political geography of French international science during the nineteenth century Transactions of the Institute of British Geographers 19 21-45

Heffernan M 2007 The new cosmopolitanism: European geographies for the $21^{\text {st }}$ century in The European geographical imagination Franz Steiner Verlag, Stuttgart 63-87

Heffernan M and Jöns H 2013 Research travel and disciplinary identities in the University of Cambridge, 1885-1955 The British Journal for the History of Science 46 255-86

Henning S 1999 Foreign-born Germans in the United States: where are they migrating and why? Erdkunde 53 177-90

Ho EL-E 2011 'Claiming' the diaspora: elite mobility sending state strategies and the spatialities of citizenship Progress in Human Geography 35 757-72

Hoerder D 2002 The German-language diasporas: a survey, critique, and interpretation Diaspora 11 7-44

Hugo G 2005 Demographic trends in Australia's academic workforce Journal of Higher Education Policy and Management 27 327-43

Isaakyan I 2010 'Platoon' friendship of the Soviet academic diaspora Studies in Ethnicity and Nationalism 10 271-89

Jansen C 2004 Exzellenz weltweit: Die Alexander von Humboldt-Stiftung zwischen Wissenschaftsförderung und auswärtiger Kulturpolitik (1953-2003) Unter Mitarbeit von Christoph Nensa Dumont, Cologne

Jöns H 2002 Internationalität durch ausländische Gastwissenschaftler in Institut für Länderkunde ed Nationalatlas Bundesrepublik Deutschland: Bildung und Kultur Spektrum Akademischer Verlag, Heidelberg 84-5 
Jöns H 2003 Grenzüberschreitende Mobilität und Kooperation in den Wissenschaften University of Heidelberg, Heidelberg

Jöns H 2007 Transnational mobility and the spaces of knowledge production Social Geography 2 97-114

Jöns H 2009 ‘Brain circulation’ and transnational knowledge networks: studying long-term effects of academic mobility to Germany 1954-2000 Global Networks 9 315-38

Jöns H and Hoyler M 2013 Global geographies of higher education: the perspective of world university rankings Geoforum 46 45-59

King R 2012 Geography and migration studies: retrospect and prospect Population, Space and Place 18 134-153

Krauss M 2006 'Gedankenaustausch über Probleme und Methoden der Forschung': Transatlantische Gastprofessoren aus Emigrantenkreisen in Westdeutschland nach 1945 Berichte zur Wissenschaftsgeschichte 29 243-59

Krohn C-D, Von Zur Mühlen P, Paul G and Winckler L eds 1998 Handbuch der deutschsprachigen Emigration 1933-45 Wissenschaftliche Buchgesellschaft, Darmstadt

Kuznetsov Y ed 2006 Diaspora networks and the international migration of skills: how countries can draw on their talent abroad The World Bank, Washington, DC Larner W 2007 Expatriate experts and globalizing governmentalities: the New Zealand diaspora strategy Transactions of the Institute of British Geographers 32 331-45

Latour B 1987 Science in action Harvard University Press, Cambridge, MA

Leung MWH 2013 'Read ten thousand books, walk ten thousand miles': geographical mobility and capital accumulation among Chinese scholars Transactions of the Institute of British Geographers 38 311-24 
Littmann U 1996 Gute Partner - schwierige Partner: Anmerkungen zur akademischen Mobilität zwischen Deutschland und den Vereinigten Staaten von Amerika (19231993) DAAD, Bonn

Mavroudi E 2007 Diaspora as process: (de)constructing boundaries Geography Compass 1 467-79

Meusburger P and Schuch T eds 2012 Wissenschaftsatlas of Heidelberg University Bibliotheca Palatina, Heidelberg

Meyer J-B 2001 Network approach versus brain drain: lessons from the diaspora International Migration 39 91-108

Mitchell K 1997 Different diasporas and the hype of hybridity Environment and Planning D 15 533-53

Ní Laoire C 2003 Editorial introduction: locating geographies of diaspora International Journal of Population Geography $9275-80$

Nussbaum MC 1997 Cultivating humanity: a classical defense of reform in liberal education Harvard University Press, Cambridge, MA

NSB eds 1998 Science and engineering indicators 1998 National Science Board, Arlington VA

Pagden A ed 2002 The idea of Europe: from antiquity to the EU Cambridge University Press, Cambridge

Pietsch T 2010 Wandering scholars? Academic mobility and the British World 1850-1940 Journal of Historical Geography 36 377-87

Pile S 2010 Emotions and affect in recent human geography Transactions of the Institute of British Geographers 35 5-20

Rupke NA 2005 Alexander von Humboldt: a metabiography Peter Lang, Frankfurt Savage M, Bagnall G, Longhurst, B 2005 Globalization and belonging Sage, London 
Saxenian A 2006 The new argonauts Harvard University Press, Cambridge, MA

Smith MP, Favell A eds 2006 The human face of global mobility: international highly skilled migration in Europe, North America and the Asia-Pacific. Transaction Publishers, New Brunswick, NJ

Solimano A 2008 Causes and consequences of talent mobility in Solimano A ed The international mobility of talent: types, causes, and development impact Oxford University Press, Oxford 1-18

Tsagarousianou R 2004 Rethinking the concept of diaspora: mobility, connectivity and communication in a globalised world Westminster Papers in Communication and Culture $152-65$

US Census Bureau 2013 America's foreign-born in the last 50 years US Department of Commerce, Washington, DC http://www.census.gov/how/infographics/foreign born.html (last accessed 14 February 2014)

Welch A 2008 Myths and modes of mobility: the changing face of academic mobility in the global era in Byram $\mathbf{M}$ and Dervin $\mathbf{F}$ eds Students, staff and academic mobility in higher education Cambridge Scholars Publishing, Newcastle 292-311

Welch A and Zhang Z 2008 Higher education and global talent flows: brain drain, overseas Chinese intellectuals and diasporic knowledge networks Higher Education Policy 21 $519-37$

Zeleza PT 2004 The African academic diaspora in the United States and Africa: the challenges of productive engagement Comparative Studies of South Asia, Africa and the Middle East 24 261-77 


\section{Figures}

Figure 1 Circular academic mobility to Germany funded by the Humboldt Foundation

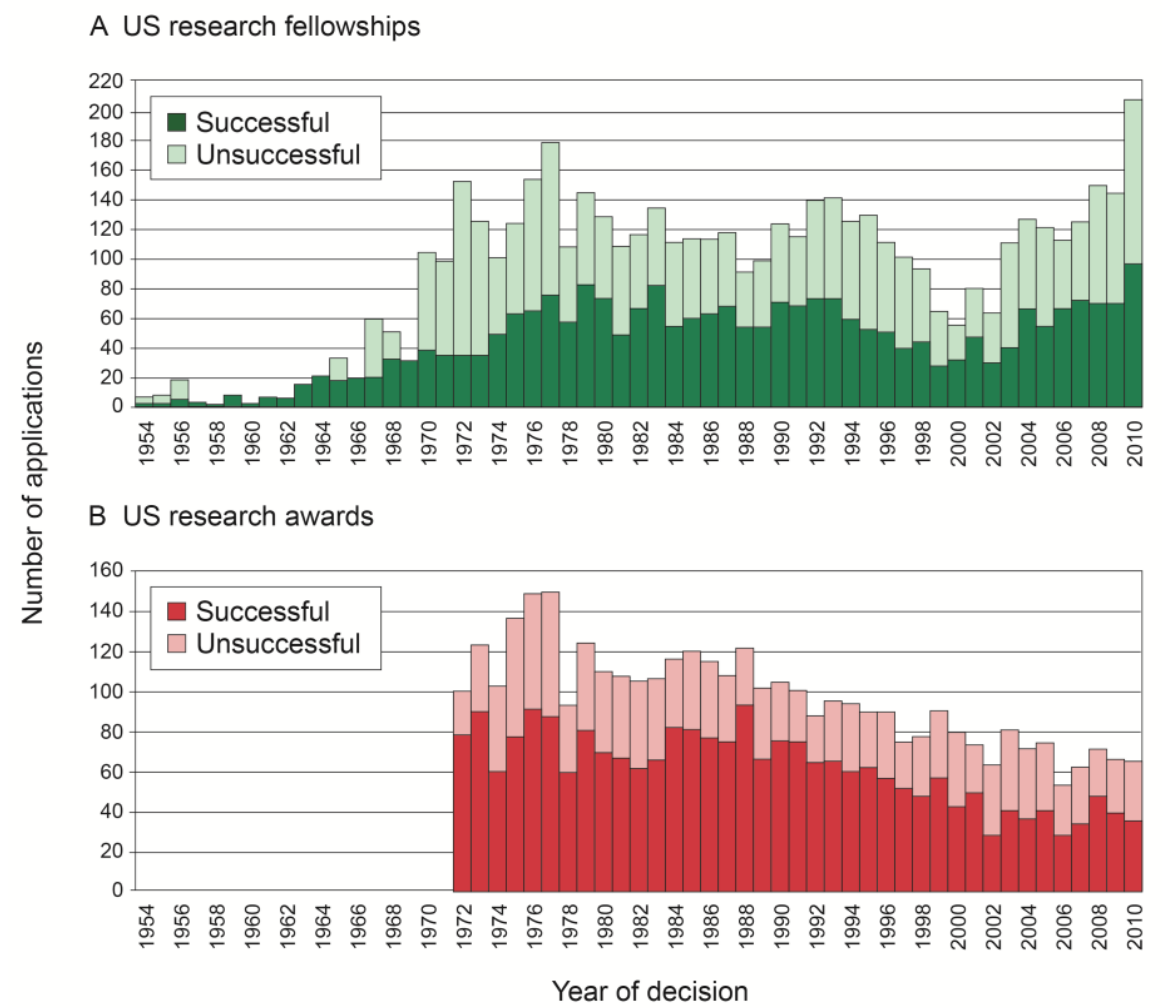

Source: Published annual reports of the Humboldt Foundation and http://www.humboldt-

foundation.de (last accessed 14 February 2014). 
Tables

Table I Contribution of Humboldt research fellows and awardees to US-German knowledge networks (in per cent)

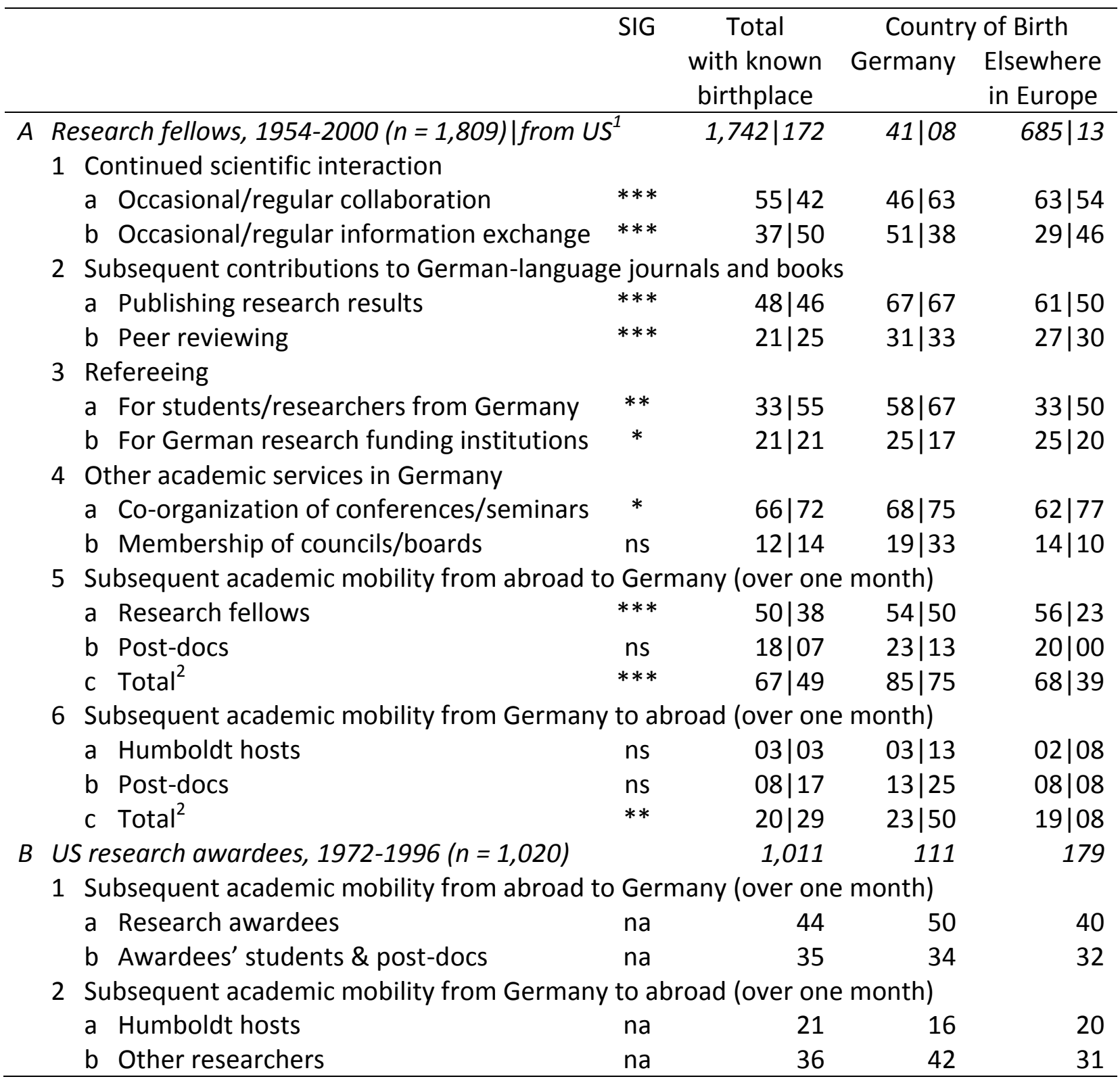

SIG Statistically significant differences between all research fellows born in Germany, in other European countries, and elsewhere: ns $=$ not on $5 \%$ level, $*=$ on $5 \%$ level, $* *=$ on $1 \%$ level, ${ }^{* * *}=$ on $0.1 \%$ level, na $=$ not applicable (total survey: $65 \%$ response)

1 Due to the sample size of US research fellows $(n=182)$, displayed differences are not statistically significant. Chi-square results relate to research fellows from all countries of origin. Their shares may show different trends to the US situation (as displayed in second figure) because of country-specific variations.

2 This includes travels of students (from first degree studies to doctoral level), post-docs, professors, and other researchers that resulted from the research fellows' contacts.

Source: Own postal surveys of US Humboldt research award winners, 1972-1996, and Humboldt research fellows, 1954-2002. 
Table II Contribution of Humboldt research fellows to US-German knowledge networks by their place of birth and prior contacts in Germany (in per cent)

\begin{tabular}{|c|c|c|c|c|c|c|}
\hline \multirow[b]{2}{*}{$A$} & \multirow[b]{2}{*}{ Prior academic contacts, $1954-2000 \mid$ from US ${ }^{1}$} & \multirow[t]{2}{*}{ SIG } & \multicolumn{2}{|c|}{$\begin{array}{l}\text { Born outside } \\
\text { Europe } \\
n=584\end{array}$} & \multicolumn{2}{|c|}{$\begin{array}{c}\text { Born in } \\
\text { Germany } \\
n=27\end{array}$} \\
\hline & & & Yes & No & Yes & No \\
\hline & 1 Continued scientific interaction & & & & & \\
\hline & a Occasional/regular collaboration & $* * *$ & $54 \mid 41$ & $35 \mid 34$ & $43 \mid 57$ & $67 \mid 100$ \\
\hline & b Occasional/regular information exchange & $* * *$ & $39 \mid 53$ & $53 \mid 47$ & $57 \mid 43$ & $33 \mid 00$ \\
\hline & 2 Subsequent academic mobility of research fe & lows t & German & & & \\
\hline & a Long visits (over one month) & ns & $47 \mid 36$ & $40 \mid 40$ & $58 \mid 43$ & $60 \mid 100$ \\
\hline & b Short visits (up to one month) & $*$ & $48 \mid 57$ & $39 \mid 55$ & $74 \mid 86$ & $20 \mid 100$ \\
\hline \multirow[t]{7}{*}{$B$} & Prior private contacts, $1954-2000 \mid$ from US ${ }^{1}$ & & Yes & No & Yes & No \\
\hline & 1 Continued scientific interaction & & & & & \\
\hline & a Occasional/regular collaboration & $*$ & $52 \mid 42$ & $42 \mid 34$ & $44 \mid 57$ & $100 \mid 100$ \\
\hline & b Occasional/regular information exchange & $*$ & $42 \mid 53$ & $48 \mid 49$ & $56 \mid 43$ & $00 \mid 00$ \\
\hline & 2 Subsequent academic mobility of research fe & lows & German & & & \\
\hline & a Long visits (over one month) & $*$ & $48 \mid 43$ & $39 \mid 27$ & $55 \mid 43$ & $100 \mid 100$ \\
\hline & b Short visits (up to one month) & $* * *$ & $51 \mid 58$ & $36 \mid 52$ & $64 \mid 86$ & $50 \mid 100$ \\
\hline
\end{tabular}

SIG Statistically significant differences between all research fellows born outside of Europe: ns $=$ not on $5 \%$ level, ${ }^{*}=$ on $5 \%$ level, ${ }^{* *}=$ on $1 \%$ level, $* * *=$ on $0.1 \%$ level.

1 Due to the sample size of US research fellows $(n=182)$, displayed differences are not always statistically significant. Chi-square results relate to research fellows from all countries of origin. Their shares may show different trends to the US situation (as displayed in second figure) because of country-specific variations.

Source: Own postal surveys of Humboldt research fellows, 1954-2002. 


\footnotetext{
'Note that the cited definition of 'affinity diaspora' is still framed by 'ethno'-national rhetoric. It mentions 'ethnic' and 'national' identities and uses the nation-state as its only point of reference.

ii The grandfather of this scientist was a Lt. Colonel in the Austrian army and received the highest imperial decoration, the 'Goldene Verdienstkreuz mit Krone am Band der Tapferkeitsmedaille'.

iii The Habilitation is a postdoctoral qualification required for permanent professorships in Germany. It is equivalent to the second book published after the PhD thesis and can also be based on an annotated collection of peer-reviewed journal articles.

${ }^{\text {iv }}$ German language skills were often not necessary for interaction in the natural sciences as English became the lingua franca in the postwar decades, but visiting scholars in the humanities often required such skills for their research and thus were more often native speakers (Jöns 2007).
} 